\title{
Psychiatric Patients with Anti-thyroid Antibodies Presenting Elevation of Serum and Cerebrospinal Fluid Anti-glutamate Receptor Antibodies
}

\author{
Tomoyuki Saito1), Yuhei Chiba ${ }^{1)}$, Kie Abe ${ }^{1)}$, Saki Hattori1), Masatoshi Miyauchi'), Omi \\ Katsuse1), Yukitoshi Takahashi²), Akira Suda1) \\ 1) Department of Psychiatry, Yokohama City University School of Medicine \\ 2) Department of Pediatrics, Shizuoka Institute of Epilepsy and Neurological Disorders
}

Objectives: The present study aims to examine antibodies against the $\mathrm{N}$-methyl-D-aspartate-type glutamate receptor (NMDAR) subunits, NR1 and NR2B, in psychiatric patients with anti-thyroid antibodies (PPATs) and in those without (nonPPATs).

Background: A high prevalence of psychiatric illnesses among people with anti-thyroid antibodies, independent of thyroid function, has been recognized recently, which implies that not only hormonal but also neuro-immunological abnormalities contribute to the relationship between psychiatric illnesses and anti-thyroid antibodies. We previously reported a high prevalence of anti-NMDAR antibodies among psychiatric patients with anti-thyroid antibodies (1). However, it remains unclear whether the presence of anti-thyroid antibodies influences anti-NMDAR antibodies among psychiatric patients.

Material and Methods: We recruited inpatients aged 20-60 years. Patients with neurological diseases, dementia, developmental disorders, tumors, or autoimmune diseases, except autoimmune thyroiditis, were excluded. Twenty-seven subjects, who were divided into two groups according to the presence of serum antithyroglobulin antibodies and anti-thyroid peroxidase antibodies, were ultimately enrolled: eighteen PPATs and nine non-PPATs. We collected the sera and CSF of PPATs and non-PPATs as well as the sera of eighteen healthy controls (HCs) who were age- and sex-matched with PPATs. We investigated serum and CSF anti-NR1 and anti-NR2B antibodies using ELISA.
Results and conclusion: No significant differences were observed in demographic data between PPATs and non-PPATs (Table 1). The optical densities of serum anti-NR1 antibodies were significantly higher in PPATs than in HCs (Figure 1, A). The optical densities of CSF anti-NR1 (Figure 1, C) and anti-NR2B (Figure 1, D) antibodies were significantly higher in PPATs than in non-PPATs. Our finding indicates that detecting anti-thyroid antibodies in psychiatric patients would be a clue to consider anti-NMDAR encephalitis or anti-NMDAR antibody-related psychiatric conditions. Further studies focusing on the relationship between PPATs and anti-NMDAR antibodies are needed.

\begin{tabular}{|c|c|c|c|}
\hline & PPATs & Non-PPATs & P-value \\
\hline Age & $42.7 \pm 11.8$ & $34.7 \pm 12.7$ & 0.084 \\
\hline Male (\%) & $3 / 18(16.7)$ & $4 / 9(44.4)$ & 0.18 \\
\hline Duration of illness & $12.6 \pm 10.1$ & $6.9 \pm 6.7$ & 0.12 \\
\hline GAF & $24.9 \pm 12.8$ & $27.9 \pm 8.9$ & 0.23 \\
\hline Psychosis & $13 / 18(72.2 \%)$ & $7 / 9(77.8 \%)$ & 1.00 \\
\hline Catatonic features & $1 / 18(5.6 \%)$ & $2 / 9(22.2 \%)$ & 0.25 \\
\hline TSH ( $\mu \mathrm{IU} / \mathrm{mL})$ & $4.72 \pm 4.37$ & $3.00 \pm 3.45$ & 0.23 \\
\hline FT4 (ng/dL) & $1.22 \pm 0.27$ & $1.09 \pm 0.18$ & 0.16 \\
\hline $\mathrm{CRP}(\mathrm{mg} / \mathrm{dL})$ & $0.68 \pm 1.51$ & $0.13 \pm 0.17$ & 0.38 \\
\hline EEG abnormalities & $2 / 17(11.8 \%)$ & $2 / 9(22.2 \%)$ & 0.59 \\
\hline \multicolumn{4}{|c|}{$\begin{array}{l}\text { Continuous variables are expressed in mean } \pm \text { SD. Comparisons } \\
\text { between PPATs and non-PPATs were performed using the } \\
\text { Mann-Whitney U-test for continuous variables and Fisher's exact } \\
\text { test for categorical variables. }\end{array}$} \\
\hline
\end{tabular}

A

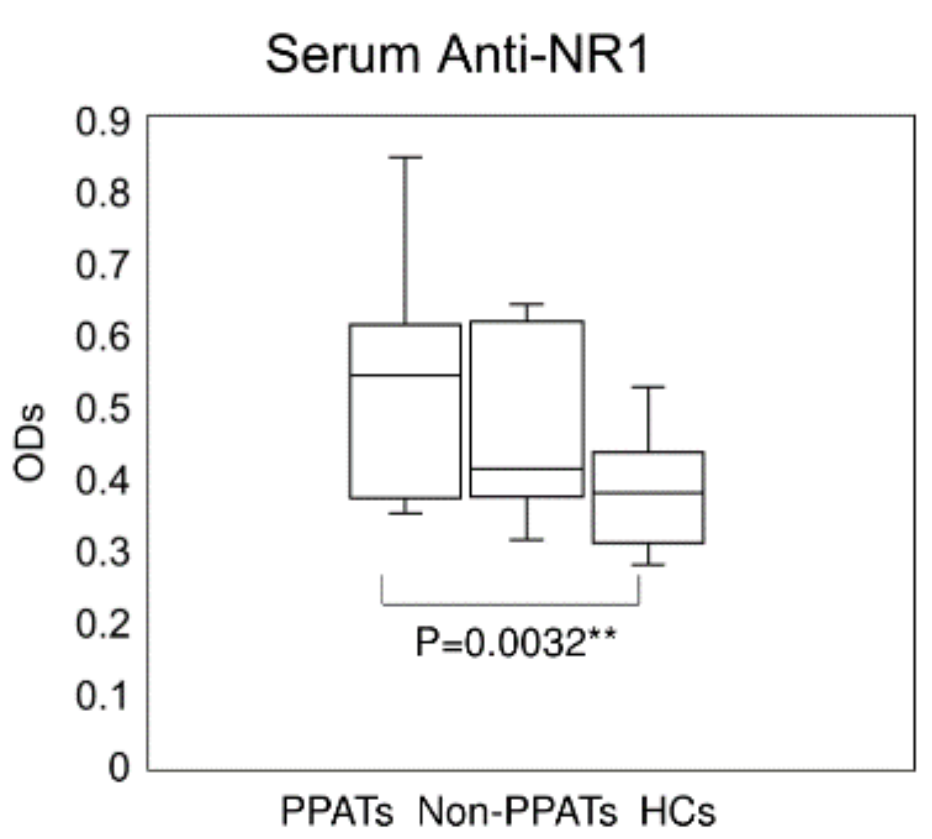

B

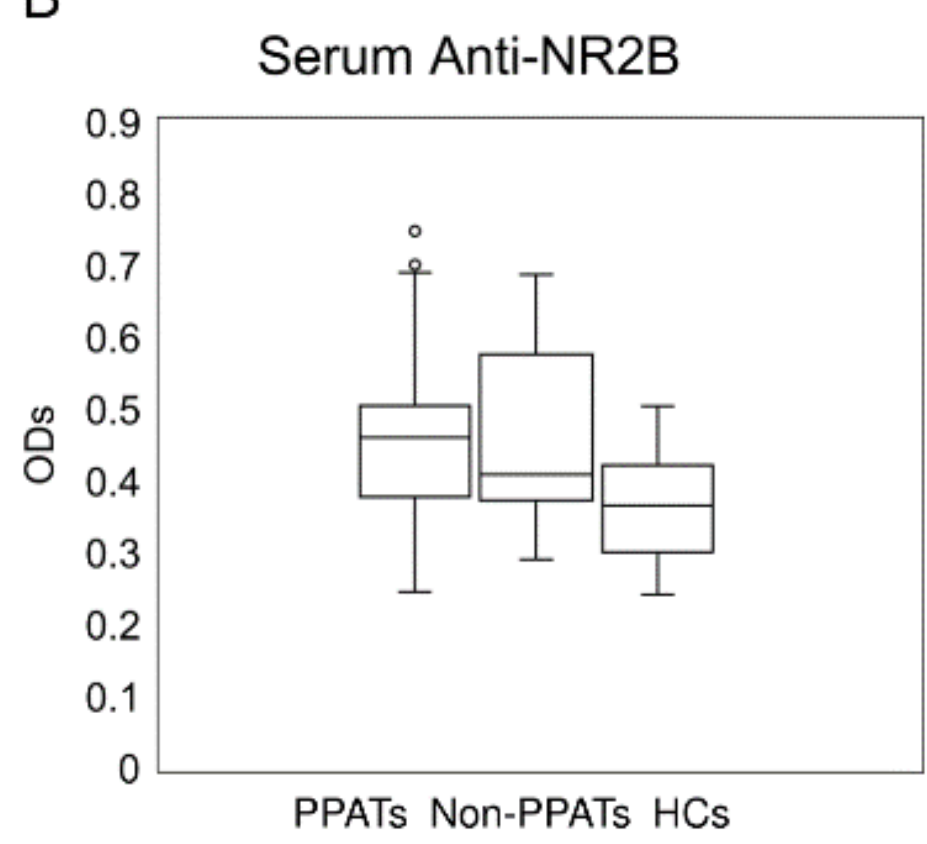

$\mathrm{C}$

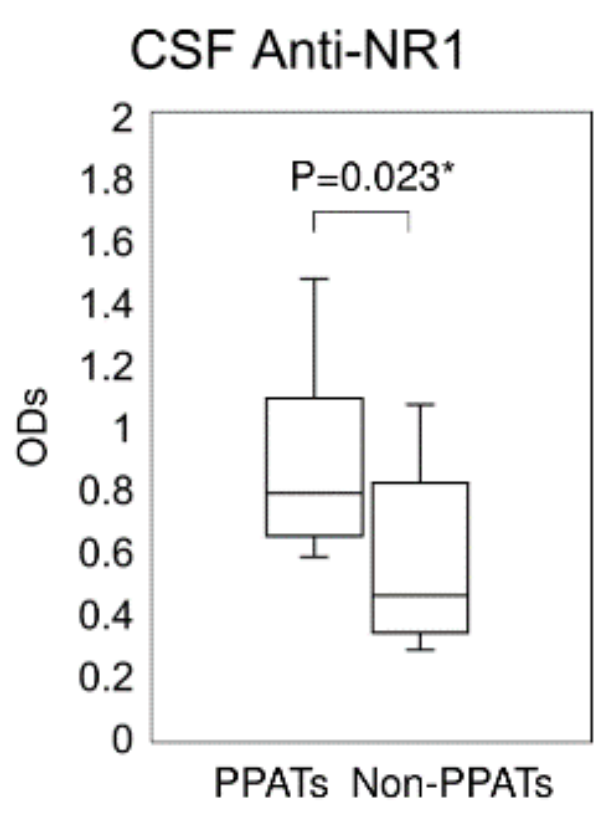

D

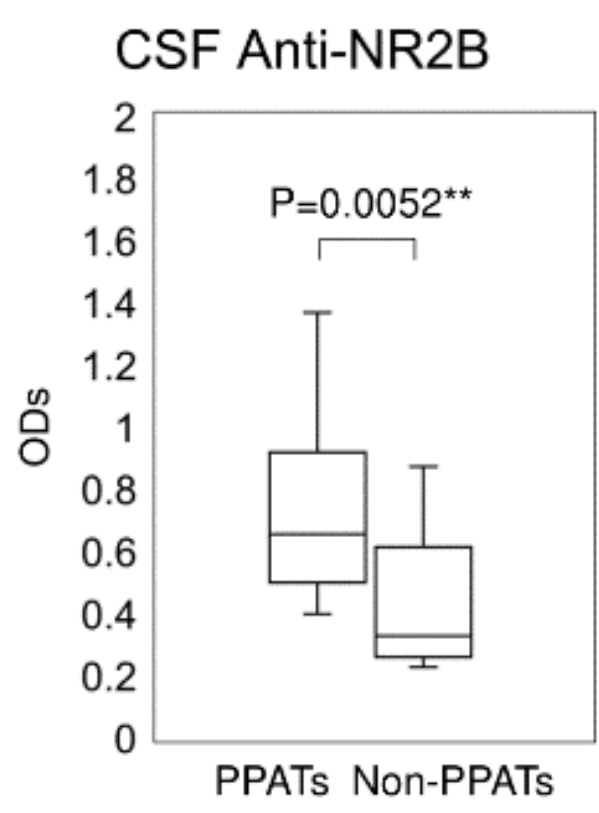

Figure 1. Comparison of Anti-NR1 and Anti-NR2 Antibodies. 